\title{
Vineyard environments influence Malbec grapevine phenotypic traits and DNA methylation patterns in a clone-dependent way
}

\author{
Anabella Varela ${ }^{1}$. Verónica N. Ibañez ${ }^{1} \cdot$ Rodrigo Alonso $^{2} \cdot$ Diego Zavallo $^{3} \cdot$ Sebastián Asurmendi $^{3}$. \\ Sebastián Gomez Talquenca ${ }^{4}$. Carlos F. Marfil ${ }^{1,5}$ - Federico J. Berli ${ }^{1,5}$ [D
}

Received: 21 July 2020 / Accepted: 30 September 2020

○) Springer-Verlag GmbH Germany, part of Springer Nature 2020

\begin{abstract}
Key message By studying three cv. Malbec clones cultivated in two vineyards with contrasting environmental conditions, we demonstrated that DNA methylation has an important role in the phenotypic plasticity and that epigenetic modulation is clone-dependent.

Abstract Clonal selection and vegetative propagation determine low genetic variability in grapevine cultivars, although it is common to observe diverse phenotypes. Environmental signals may induce epigenetic changes altering gene expression and phenotype. The range of phenotypes that a genotype expresses in different environments is known as phenotypic plasticity. DNA methylation is the most studied epigenetic mechanism, but only few works evaluated this novel source of variability in grapevines. In the present study, we analyzed the effects on phenotypic traits and epigenome of three Vitis vinifera $\mathrm{cv}$. Malbec clones cultivated in two contrasting vineyards of Mendoza, Argentina. Anonymous genome regions were analyzed using methylation-sensitive amplified polymorphism (MSAP) markers. Clone-dependent phenotypic and epigenetic variability between vineyards were found. The clone that presented the clearer MSAP differentiation between vineyards was selected and analyzed through reduced representation bisulfite sequencing. Twenty-nine differentially methylated regions between vineyards were identified and associated to genes and/or promoters. We discuss about a group of genes related to hormones homeostasis and sensing that could provide a hint of the epigenetic role in the determination of the different phenotypes observed between vineyards and conclude that DNA methylation has an important role in the phenotypic plasticity and that epigenetic modulation is clone-dependent.
\end{abstract}

Keywords Epigenetics · Differentially methylated regions (DMR) $\cdot$ MSAP $\cdot$ Phenotypic plasticity $\cdot$ RRBS $\cdot$ Vitis vinifera

Communicated by Neal Stewart.

Carlos F. Marfil and Federico J. Berli should be considered joint senior authors.

Electronic supplementary material The online version of this article (https://doi.org/10.1007/s00299-020-02617-w) contains supplementary material, which is available to authorized users.

Carlos F. Marfil

cmarfil@fca.uncu.edu.ar

$\triangle$ Federico J. Berli

fberli@fca.uncu.edu.ar

1 Facultad de Ciencias Agrarias, Instituto de Biología Agrícola de Mendoza, CONICET-Universidad Nacional de Cuyo, Alte. Brown 500, M5507, Chacras de Coria, Mendoza, Argentina

2 Catena Institute of Wine (CIW), Bodega Catena Zapata, Cobos w/n, M5509, Agrelo, Mendoza, Argentina

\section{Introduction}

Vitis vinifera $\mathrm{L}$. is a diploid species $(2 n=38$ chromosomes) highly heterozygous, with frequent occurrence of somatic mutations (This et al. 2006) and high capacity to adapt to different environments (Keller 2010). The

3 Instituto de Agrobiotecnología y Biología Molecular (IABIMO), Instituto Nacional de Tecnología Agropecuaria (INTA), Consejo Nacional de Investigaciones Científicas y Técnicas (CONICET), De Losos Reseros y N. Repetto w/n, Hurlingham B1686IGC, Buenos Aires, Argentina

4 Estación Experimental Agropecuaria Mendoza INTA, San Martín 3853, Lujan de Cuyo, Mendoza, Argentina

5 Facultad de Ciencias Agrarias, Universidad Nacional de Cuyo, Alte. Brown 500, M5507, Chacras de Coria, Mendoza, Argentina 
artificial selection of desirable traits and the asexual propagation has been carried out from the beginning of viticulture allowing the formation of cultivars. Therefore, low genetic differences within grapevines are observed.

Besides the somatic mutations, the epigenetic polymorphism is another source of variability. The epigenetic mechanisms include cytosine DNA methylation, histone post-translational modifications, and small RNAs regulation (Norouzitallab et al. 2019). DNA methylation in higher plants occurs on cytosine residues in the $\mathrm{CpG}$, $\mathrm{CpHpG}$ and $\mathrm{CpHpH}$ ( $\mathrm{H}$ denotes nucleotides $\mathrm{A}, \mathrm{C}$ or $\mathrm{T}$ ) sequence contexts (Henderson and Jacobsen 2007; Zhang et al. 2018). Differences in DNA methylation play a role in phenotype traits as flowering time and plant height in Arabidopsis thaliana (Johannes et al. 2009). DNA methylation contributes to the adaptation of perennial species with low genetic variation to changing environments; as in Pinus pinea L. (Sáez-Laguna et al. 2014) and Populus tremuloides (Ahn et al. 2017).

The phenotypic plasticity is defined as the capacity of a genotype to express different phenotypes when exposed to different environments throughout its ontogeny (Pigliucci 2005). Grapevine is considered one of the most environmentally sensitive crops and has a broad phenotypic plasticity (Dal Santo et al. 2016). However, the knowledge of grapevine epigenome and its effect on the phenotypic plasticity are limited (Fabres et al. 2017). Previous studies showed changes in grapevine DNA methylation induced by harsh environmental conditions like in vitro cultivation (Baránek et al. 2015; Schellenbaum et al. 2008), high ultraviolet$\mathrm{B}$ and $\mathrm{C}$ radiation (UV-B and UV-C) (Marfil et al. 2019; Tyunin and Kiselev 2016), and kaolin treatments (Bernardo et al. 2017).

The wine industry often relates wine sensory attributes to its geographic origin using the French term terroir (Fabres et al. 2017). Terroir refers to the complex interactions between the genotype, the environment and human cultural practices, and there are approaches in the literature to understand the concept objectively. Environment-dependent changes in the transcriptome and metabolome were evaluated for a single clone of $V$. vinifera $\mathrm{cv}$. Corvina in three macrozones of Verona (Italy) during 3 years. Results showed secondary metabolism transcripts mostly influenced by season (Dal Santo et al. 2013) and berries' metabolic profiles associated with each macrozone (Anesi et al. 2015). In addition, Dal Santo et al. (2016) evaluated a V. vinifera cv. Garganega clone cultivated in four sites of Verona and found site-dependent gene expression of the phenylpropanoid and flavonoid pathways. Moreover, comparison between cultivars showed that the Garganega berries were more plastic than Corvina, particularly in the accumulation of phenolic compounds. These results demonstrated that grapevine cultivars may differ in the phenotypic plasticity for some traits.
The inclusion of epigenomic data is necessary to understand the environmental effect on grapevine phenotypes (Fabres et al. 2017). Xie et al. (2017) analyzed the molecular diversity of cv. Shiraz in 22 vineyards of Australia and observed low genetic differentiation, but a high level of epigenetic variation between vineyards. Similarly, we previously found DNA methylation patterns of cv. Malbec that changed in response to UV-B, water restriction and abscisic acid (ABA) treatments (Marfil et al. 2019). We showed DNA methylation patterns that are mitotically heritable, affecting the hydroxycinnamic acids accumulation in the early fruit shoots.

There are few studies in field experiments with plants exposed to multiple environmental stimuli. In the present study, we evaluate the role of DNA methylation in the phenotypic plasticity of three Malbec clones cultivated in two environmentally contrasting vineyards. Clone-dependent responses and correlations between environmentally induced epigenetic and phenotypic changes were detected. We identified epigenetic changes in gene and promoter regions and discussed the function of those genes and their possible relationship with the differences observed in the phenotypic traits. Future research will be focused on assessing the impact of these promoter and gene body methylation differences on gene expression and grapevine phenotype.

\section{Materials and methods}

\section{Plant material}

The study was performed using $V$. vinifera $\mathrm{cv}$. Malbec clones MB01, MB04 and MB10 (Catena Institute of Wine, Bodega Catena Zapata) cultivated in Agrelo (68 $54^{\prime} 40^{\prime \prime} \mathrm{W}, 33^{\circ}$ $09^{\prime} 58^{\prime \prime} \mathrm{S}$; $955 \mathrm{~m}$ a.s.1.) and Gualtallary $\left(69^{\circ} 14^{\prime} 54^{\prime \prime} \mathrm{W}\right.$, $33^{\circ} 23^{\prime} 42^{\prime \prime}$ S; 1343 m a.s.l.), Mendoza, Argentina (Fig. 1a). Vineyards were selected to maximize the differences in environmental conditions, while minimizing the differences in cultural practices. Between the two vineyards, there is a linear distance of $41 \mathrm{~km}$ and an altitude difference of $388 \mathrm{~m}$ (Fig. 1a). There are differences in the soil types, being sandy loam with clay at $0.3-0.6 \mathrm{~m}$ depth in Agrelo and sandy in Gualtallary. Grapevines were planted in Agrelo and Gualtallary during the years of 1995 and 1999, respectively, with anti-hail nets only in Gualtallary. In both sites, grapevines were planted on their own roots, with a planting density of 4000 vines/ha, trained on a vertical trellis system, cane pruned to 14-16 buds, arranged in north-south oriented rows ( $2 \mathrm{~m}$ row spacing and $1.25 \mathrm{~m}$ between plants), and maintained with a drip irrigation system.

In 2016-2017 growing season, when the shoots reached $10 \mathrm{~cm}$ long, stage 12 (Coombe 1995), five plants (biological replicates; $n=5$ ) per clone and vineyard were selected (based 
a
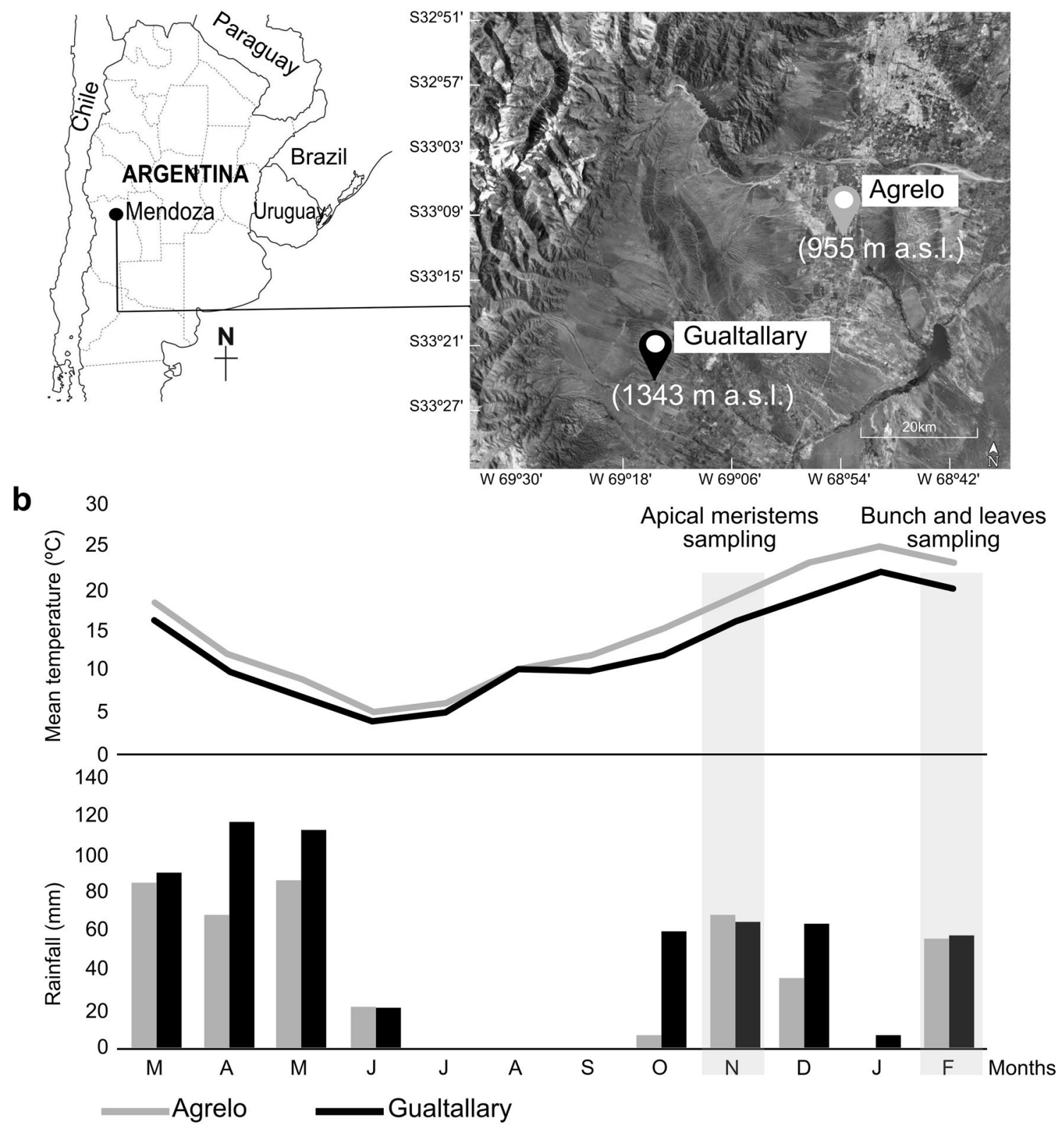

Fig. 1 Overview of the experimental site locations in Agrelo and Gualtallary, Mendoza province, Argentina, planted with Vitis vinifera cv. Malbec clones (a). 2016-2017 growing season daily mean air temperatures, monthly rain fall records and sampling dates (b)

on their trunk diameter homogeneity and located in different panel) and used to collect apical meristems for DNA extraction and molecular analyses. Samples were chilled with ice in the field, frozen with liquid nitrogen in the laboratory and then kept at $-80^{\circ} \mathrm{C}$ until processing. At stage 38 (Coombe 1995), one shoot per experimental unit was chosen and the basal bunch and its opposite leaf were extracted and used for a phenotypic characterization. Samples were placed in nylon bags, kept on ice and carried to the laboratory where bunch and berry fresh weight were determined. The berries were stored at $-20{ }^{\circ} \mathrm{C}$ until further analyses.

\section{Meteorological data}

The daily mean air temperature was calculated measuring the air temperature for each vineyard every $15 \mathrm{~min}$ from March 2016 to February 2017, with HOBO temperature data loggers (Onset Computer Corporation, Bourne, MA, USA), located at a height of $1.5 \mathrm{~m}$ above the ground and housed in a weather instrument shelter, close to the experimental sites. Daily rainfall was monitored using a cylindrical rain gauge placed at a distance of $2 \mathrm{~m}$ from the weather shelter. 


\section{Phenotypic analyses}

Sixteen phenotypic traits were measured: trunk diameter (at $65 \mathrm{~cm}$ from ground level), bunch fresh weight (FW), number of berries per bunch (\# berries), berry FW, berry dry weight (DW; dried at $60{ }^{\circ} \mathrm{C}$ to a constant weight), berry water content (estimated as berry FW-berry DW), berry total soluble solids (TSS) in concentration (TSS conc) and TSS in a per berry basis (TSS abs), number of seeds per berry (\# seeds), berry skin DW, berry skin total anthocyanins (TA conc and TA abs), berry skin polyphenolic content (TP conc and TP abs), specific leaf area (SLA), and leaf DW (Supplementary Data S1).

The berry TSS accumulation and berry skin phenolics were determined according to Berli et al. (2011) using a Pocket PAL-1 digital hand-held refractometer (Atago Co., Ltd., Tokyo, Japan) and a Cary UV-Vis spectrophotometer (Varian Inc., CA, USA), respectively. Berry skins were separated from pulps and seeds by hand and after phenolic extraction, the berry skins were dried at $60^{\circ} \mathrm{C}$ until constant weight. The leaf area (LA) was estimated by digital images using the Easy Leaf Area software (Easlon and Bloom 2014). Then, samples were dry weight (DW; leaf dried at $60{ }^{\circ} \mathrm{C}$ to a constant weight) and the leaf DW per area (SLA) was calculated.

\section{DNA extraction and methylation-sensitive amplified polymorphism (MSAP) analysis}

Genomic DNA was extracted from the apical meristem following the protocol described by Lodhi et al. (1994), replacing the extraction with chloroform: octanol by chloroform: isoamyl alcohol. After measuring the quantity and quality of the DNA by spectrophotometry (Ampliquant AQ-07 spectrophotometer), the samples were diluted to $50 \mathrm{ng} / \mu \mathrm{l}$.

DNA samples were treated according to the MSAP protocol described by Cara et al. (2013). This analysis allows the evaluation of methylation patterns of anonymous sequences distributed throughout the genome by selective PCR amplification of digested fragments using the restriction enzymes EcoRI, HpaII, and MspI. HpaII and MspI are isoschizomers with differential sensitivity to the methylation of the cytosines present in the 5'-CCGG cleavage site. Fragments obtained from the digestion with EcoRI/HpaII indicate that an external cytosine is hemimethylated, while those obtained with EcoRI/MspI indicate a methylation in the internal cytosine (Schulz et al. 2013). The presence of fragments in both digestions indicates that cytosines are non-methylated. Finally, the absence of fragments in both amplifications gives rise to an ambiguous interpretation since it may be due to a complete methylation or to a mutation in the nucleotide sequence of the restriction site (Supplementary Fig. S1a). Two selective fluorescent-labeled *EcoRI primers (FAM) were combined with three HpaII/MspI primers chosen for their polymorphism and repeatability in a previous assay. The amplification products were electrophoretically separated using the LIZ1200 marker (GeneScan ${ }^{\mathrm{TM}}$ ) and the ABI PRISM 3500 genetic analyzer (Applied Biosystems, Foster City, CA, USA) at the Genomics/Platform Node Genome CATG Unit of the National Institute of Agricultural Technology (INTA), Buenos Aires, Argentina.

The electropherograms were analyzed with GeneMarker software V2.7.0 (SoftGenetics, PA, USA) taking into account sizes between 100 and $600 \mathrm{bp}$ and a threshold of 50 RFU (Relative Fluorescent Units). Electropherograms were manually checked. Presence/absence of MSAP fragments were codified in a binary matrix of $1 / 0$, and transformed into a matrix of methylation patterns from 0 to $3(0$, ambiguous; 1 , non-methylated; 2 , hemimethylated; 3 , methylated; Supplementary Fig. S1a). Loci that were hemimethylated or methylated in one or more plants were considered as epigenetic loci ('epiloci' hereafter). Epiloci were coded in a binary matrix and used for the study of the epigenetic variability. Methylation patterns present only in a single individual (singletons) were considered artifacts and excluded from the analysis (Bonin et al. 2004; Supplementary Fig. $\mathrm{S} 1 b)$. The methylation level was calculated as the percentage of non-methylated, methylated or hemimethylated loci per clone and site of cultivation (Cara et al. 2013), and the epigenetic differences were analyzed using only polymorphic epiloci. To estimate the error rate of the MSAP technique, two plants from each vineyard (four plants in total) were randomly selected and analyzed per duplicate, starting from independent DNA extraction.

The genetic variability among and within clones was evaluated because after many cultivation years, the grapevine clones may have accumulated somatic mutations, inducing phenotypic differences (This et al. 2006). To this end, loci that were non-methylated and/or ambiguous in all analyzed plants were considered as genetic loci and used to analyze the genetic variability (Marfil et al. 2009; see below in "Molecular data (genetic and epigenetic)" section).

\section{Reduced representation bisulfite sequencing (RRBS) and bioinformatic analysis}

Based on the MSAP results, the clone MB10 was selected for the RRBS assay. Three virus-free plants (see "Virus analysis" section) from each vineyard were selected to analyze with Premium RRBS kit (Diagenode ${ }^{\circledR}$, https://www. diagenode.com/). RRBS libraries were constructed with $100 \mathrm{ng}$ of genomic DNA digested with MspI according to the manufacturer's instructions and validated using a Bioanalyzer analysis system (Agilent, Santa Clara, USA). DNA fragments were then bisulfite-converted and amplified using PCR. Libraries were sequenced with the Illumina 
NextSeq 550 platform (Illumina, USA) in single-end 75-bp runs. Raw sequencing data quality was evaluated using FastQC software (Babraham Institute, https://www.babra ham.ac.uk/). Adaptor sequences and low-quality reads were trimmed using Trim Galore (Babraham Institute). Bisulfite conversion rate was higher than $99 \%$; it was estimated by processing the spike-in-controls (sequence with all their C's unmethylated) included in the RRBS kit. Cleaned reads were aligned to the grapevine reference genome (Vitis vinifera 12X.44; Jaillon et al. 2007) using Bismark v0.22 (Babraham Institute). Methylation calling output files from Bismark were used as input to methylKit $\mathrm{R}$ package (Akalin et al. 2012) to determine differentially methylated regions (DMRs) and differentially methylated cytosine (DMCs) between vineyards. A minimum coverage of $10 \mathrm{X}$ and bins size of $1000 \mathrm{nt}$ were fixed for the analysis. Differences of $25 \%$ for $\mathrm{CpG}, 10 \%$ for $\mathrm{CHG}$ and $10 \%$ for $\mathrm{CHH}$ were considered to determine the DMR and DMC. In-house scripts were used to correlate DMRs to genes and promoters. Genes and promoters associated with DMRs regions were identified using UniProt database (https://www.uniprot.org/) and Gene Ontology annotations were assigned using PANTHER Classification System (https://www.pantherdb.org/).

\section{Virus analysis}

The MB10 plants were analyzed to select virus-free plants for RRBS analysis since stress can induce changes in DNA methylation (Chinnusamy and Zhu 2009). Two-node canes from each analyzed plant were collected during October 2018. Total RNA was extracted as described in Gambino et al. (2008). Its quality was determined by non-denaturing agarose gel electrophoresis, after that was random-primed and reverse-transcribed. The cDNA was evaluated by PCR amplifying the $18 \mathrm{~S}$ ribosomal gene (Gambino and Gribaudo 2006). The cDNA was subsequently amplified by PCR to assess the presence of Grapevine Fanleaf Virus (GFLV), Arabis Mosaic Virus (ArMV), Grapevine Virus A (GVA), Grapevine Virus B (GVB), Grapevine Fleck Virus (GFkV), Rupestris Stem Pitting-associated Virus (RSPaV) and Grapevine Leafroll-associated Virus (GLRaV)-1, -2, -3 , using the primers described by Gambino and Gribaudo (2006) and for GLRaV-4 using the primers described by Poojari et al. (2016).

\section{Statistical analysis}

\section{Phenotypic traits}

A multifactorial ANOVA was used to test the effects of clone, vineyard and their interactions for each trait, using LSD Fisher comparison test $(P \leq 0.05)$. A dendrogram of phenotypic standardized Euclidean distance generated with
UPGMA and a Principal Components Analysis (PCA) together with its biplot graph were performed with InfoStat software (InfoStat version 2009, Grupo InfoStat, Córdoba, Argentina).

\section{Molecular data (genetic and epigenetic)}

Genetic and epigenetic data obtained with the MSAP markers were analyzed separately. The inter-clone genetic variability was calculated as the observed proportion of polymorphic loci among clones for all analyzed plants, while the intra-clone genetic variability was calculated as the observed proportion of polymorphic loci within the biological replicates of each clone. Dendrograms were constructed from the genetic and epigenetic Dice similarity matrix with InfoStat software (Grupo InfoStat, Córdoba, Argentina) and subjected to bootstrapping to obtain values for the reliability of the consensus dendrogram using the WinBoot program with 1000 permutations (Yap and Nelson 1996). Also, a Principal Coordinate Analysis (PCoA) was performed with polymorphic epiloci for all analyzed plants and for each clone separately, with a permutational analysis of variance (PERMANOVA), using the $\mathrm{R}$ programming language with the Vegan package (Oksanen et al. 2019). Methylation levels of clones were computed as the observed percentage of methylated, hemimethylated, and non-methylated loci (Cara et al. 2013), and evaluated with InfoStat by a generalized linear model (GLM) with log as link function for Binomial distribution.

\section{Mantel correlation tests}

Phenotypic, genetic and epigenetic differences were evaluated by Mantel correlation tests. Phenotypic-epigenetic correlations were also performed for each clone and vineyard separately. Correlations with the RRBS data were performed for each context and for groups of selected phenotypic traits. Pearson correlation coefficients $(R)$ were considered significant when $P<0.05$. Phenotypic and RRBS matrices were analyzed with Euclidean distance while MSAP genetic and epigenetic dissimilarity matrices were generated based on the Dice coefficient (Sneath and Sokal 1973).

\section{Results}

\section{Climatic variability between vineyards}

Gualtallary vineyard was more humid and colder than Agrelo during the 2016/2017 season, in line with the historic records (Fig. 1b, Supplementary Data S2). On average, Gualtallary presented $14 \mathrm{~mm}$ more rainfall and $2{ }^{\circ} \mathrm{C}$ less in temperature than Agrelo. The months with the biggest 
Gualtallary/Agrelo contrasts were October (55 $\mathrm{mm}$ rainfall) and December $\left(-4^{\circ} \mathrm{C}\right) 2016$.

\section{Phenotypic variability was observed among clones and sites}

SLA and leaf DW were not affected by clones, vineyards or clone/vineyard interaction and they were excluded from the PCA and ANOVA analyses. Clone and vineyard interaction were identified in five traits (Fig. 2). MB01 presented significant differences between vineyards in bunch FW, \# berries (per bunch), berry water content, \# seeds (per berry), skin DW, TA abs and TP abs. In Agrelo, MB01 presented heavier bunches with higher number of berries than in Gualtallary, without changing the TP and TA concentrations. The highest accumulation of TP abs and TA abs was observed in MB01/Gualtallary, without significant effects in concentration. MB 10 presented the highest values of $\varnothing$ trunk, regardless of the vineyard. In Agrelo, MB10 presented the highest TSS conc and TSS abs. Also, MB10 showed higher TP conc in Agrelo than in Gualtallary. Finally, MB04 presented no significant differences between vineyards in most of the analyzed traits (Fig. 2).

The dendrogram grouped MB01 and MB04 (Fig. 3a). MB01 showed a clear clustering based on the vineyard, in which the first two components explained $72.7 \%$ of the total

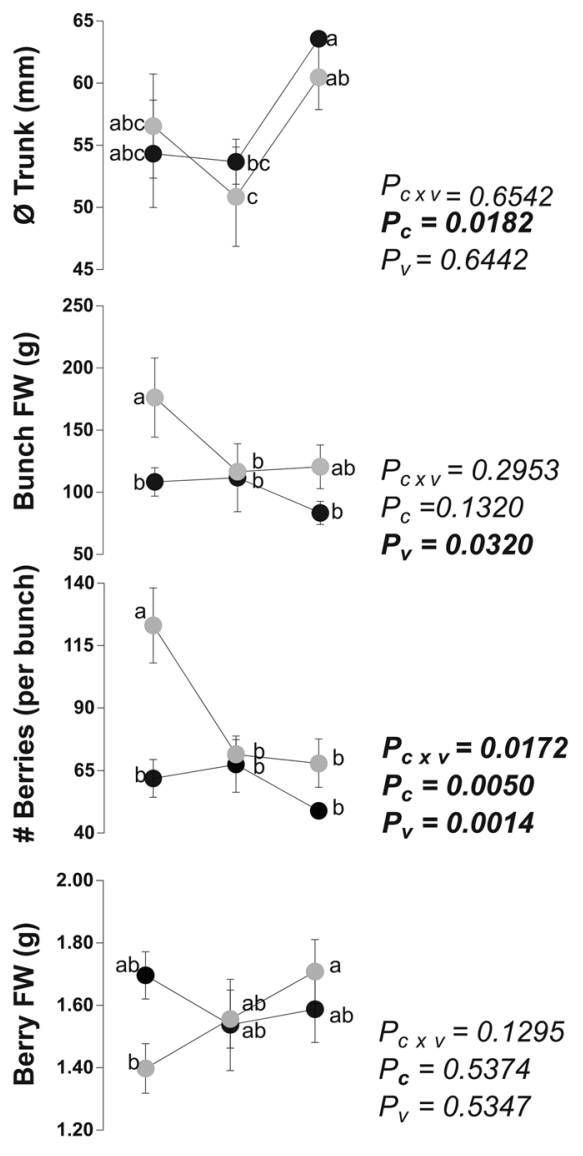

MB01 MB04 MB10

Agrelo

Gualtallary
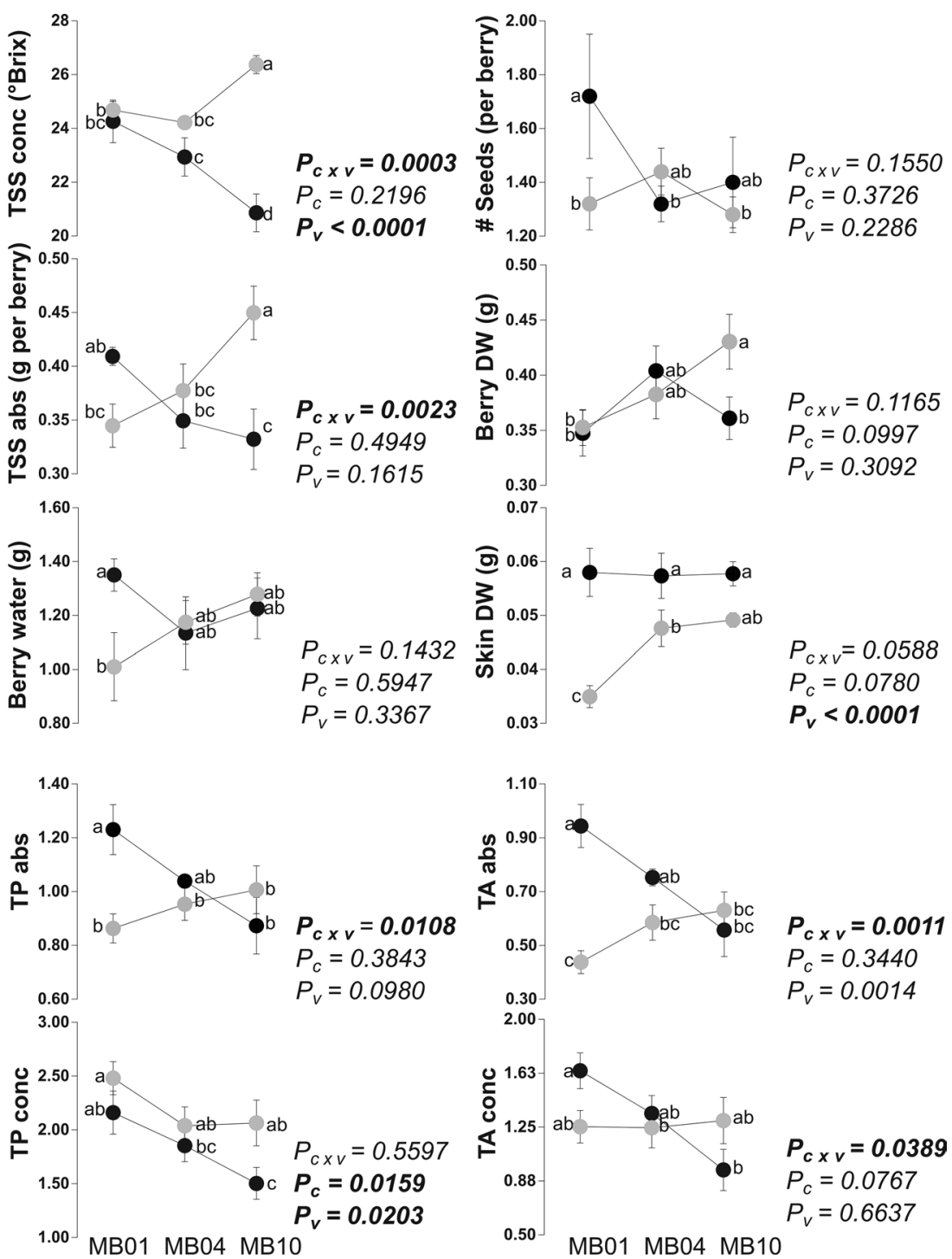

Fig. 2 Multifactorial analysis of the phenotypes of three Vitis vinifera cv. Malbec clones cultivated in two different vineyards of Mendoza, Argentina. Parameters of vigor, yield and quality traits. Values are means for each factor $(n=5) \pm$ SEM and different letters indicate significant differences (Fisher's LSD, $P \leq 0.05$ ). The effects on pheno- type of clones $(\mathrm{Pc})$; vineyards $(\mathrm{Pv})$ and interaction clones $\times$ vineyards (Pcxv) were established. $\varnothing$ trunk trunk diameter, \# berries number of berries, $F W$ fresh weight, $D W$ dry weight, TSS total soluble solutes, $T A$ total anthocyanins, $T P$ total polyphenols, conc concentration, $a b s$ absolute amounts 
a
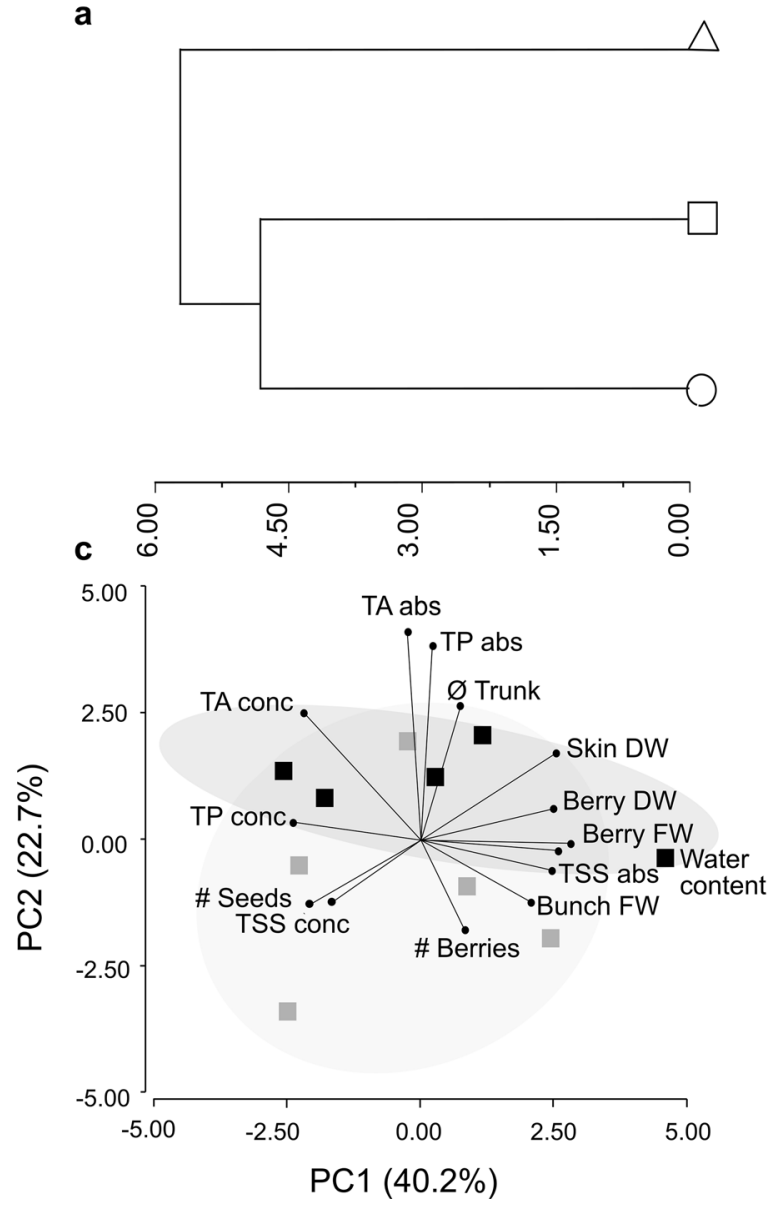

Fig. 3 Phenotypic variability in three Vitis vinifera cv. Malbec clones cultivated in two contrasting vineyards. Dendrogram of phenotypic Euclidea distance generated with UPGMA (a). Biplot visualization and 0.95 confidence ellipses of the Principal Component Analysis of phenotypic traits in three cv. Malbec clones in two vineyards (b-d).

variance. Also, the fruit yield traits as \# berries (per bunch) and bunch FW were associated with Agrelo (Fig. 3b). No clustering according to vineyard was observed for MB04, with the $62.9 \%$ of the total variance explained by the first two components (Fig. 3c). For MB10, the first two components explained $64.5 \%$ of the total variance and partial differentiation between vineyards was observed with Skin DW associated with Gualtallary (Fig. 3d).

\section{MSAP markers confirmed genetic differences among clones revealing low genetic variability within clones}

The three primer combinations amplified 732 fragments, which were evaluated as different loci (Table 1, Supplementary Data S3). The error rate calculated from four duplicated samples was $5.3 \%$. The primer combination *AAG/AAT

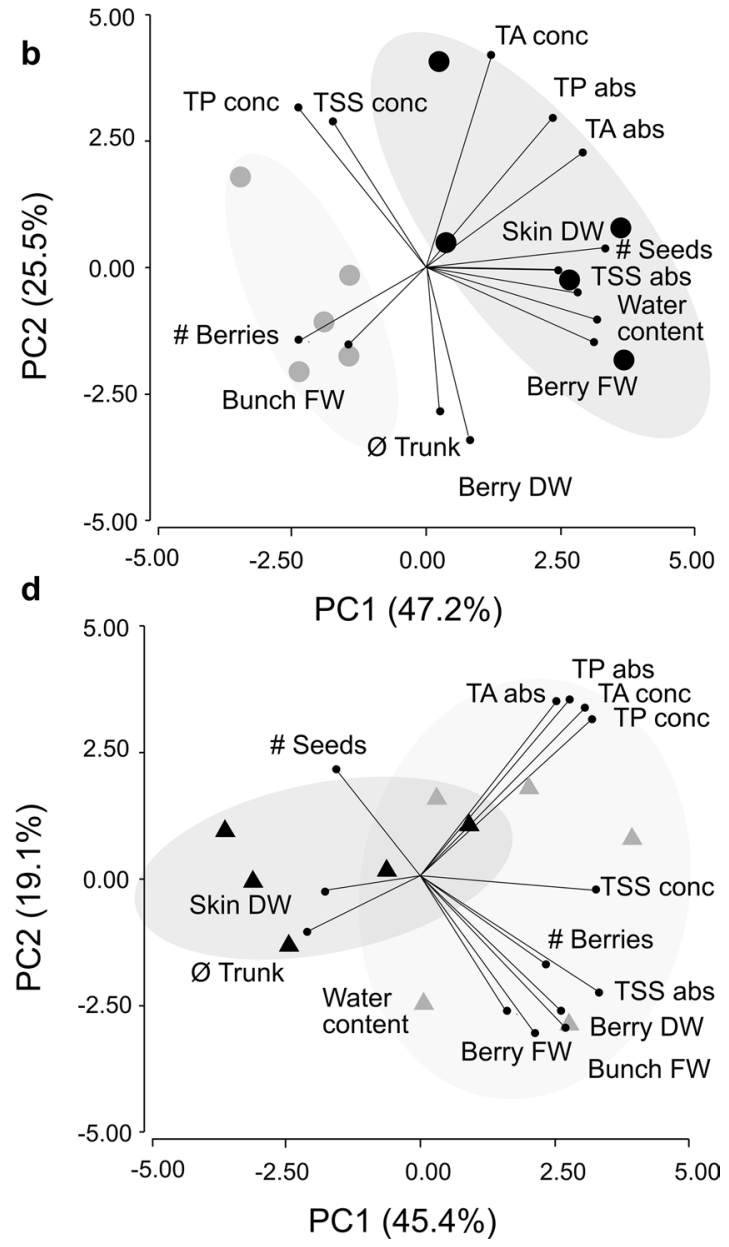

Clones MB01 (filled circle), MB04 (filled square), and MB10 (filled triangle); vineyards Agrelo (gray) and Gualtallary (black). $\emptyset$ trunk trunk diameter, \# berries number of berries, $F W$ fresh weight, $D W$ dry weight, TSS total soluble solutes, TA total anthocyanins, TP total polyphenols, conc concentration, abs absolute

Table 1 Methylation sensitive amplified polymorphism (MSAP) fragments obtained in Agrelo and Gualtallary vineyards for three Vitis vinifera $\mathrm{cv}$. Malbec clones

\begin{tabular}{llll}
\hline Fragments & Genetic loci & Epiloci & Total \\
\hline Monomorphic & $35(56 \%)$ & $15(2 \%)$ & - \\
Singletons & $14(23 \%)$ & $160(24 \%)$ & - \\
Polymorphic & $13(21 \%)$ & $495(74 \%)$ & - \\
Total & $62(8 \%)$ & $670(92 \%)$ & $732(100 \%)$ \\
\hline
\end{tabular}

Number and percentages of monomorphic, singletons and polymorphic MSAP fragments for the genetic loci and epiloci analyzed

generated $40 \%$ of the total fragments, followed by *ACG/ ATG (31\%) and *AAG/ATC (29\%) as shown in Supplementary Fig. S2. In average, each sample presented 275 fragments, with a minimum value for MB04/Gualtallary (194) and a maximum for MB01/Gualtallary (413; Supplementary 
Data S3). From the total of analyzed loci, $92 \%$ were considered as epiloci and $8 \%$ as genetic loci (Table 1; Supplementary Fig. S2).

Sixty-two loci were scored as genetic loci [since it included only non-methylated (1) or ambiguous (0) loci] and used to analyze genetic variability (Table 1). From this matrix, 14 singletons were excluded from the analysis. There were genetic differences among clones (Fig. 4). MB01 and MB04 plants grouped together at $94 \%$ of similarity, while MB 10 showed $91 \%$ of similarity with respect to the other two clones. Within each clone, there was no clustering according to vineyards of origin. MB01 and MB10 presented the greatest inter-clone variability (15\%) while MB01 and MB04 the lowest (2\%). The intra-clone variability of the polymorphic loci was $6 \%, 8 \%$ and $0 \%$ for MB01, MB04 and MB10, respectively.

\section{MSAP methylation patterns reveal epigenetic differences between clones and vineyards}

The number of polymorphic epiloci was higher than the polymorphism exhibited by genetic loci (Table 1 ).

Singletons and monomorphic epiloci were excluded from the analysis (Table 1). The proportion of polymorphic markers per clone ranged between 62 and 71\%, where MB01 and MB04 displayed higher levels of intra-clone polymorphism (Table 2). The 495 polymorphic epiloci were transformed into 696 epialleles (alternative methylation patterns at determined epilocus). The phenetic analysis grouped the samples into three groups according to their clone identity, except for clone MB04. Plants form clone MB10 grouped according

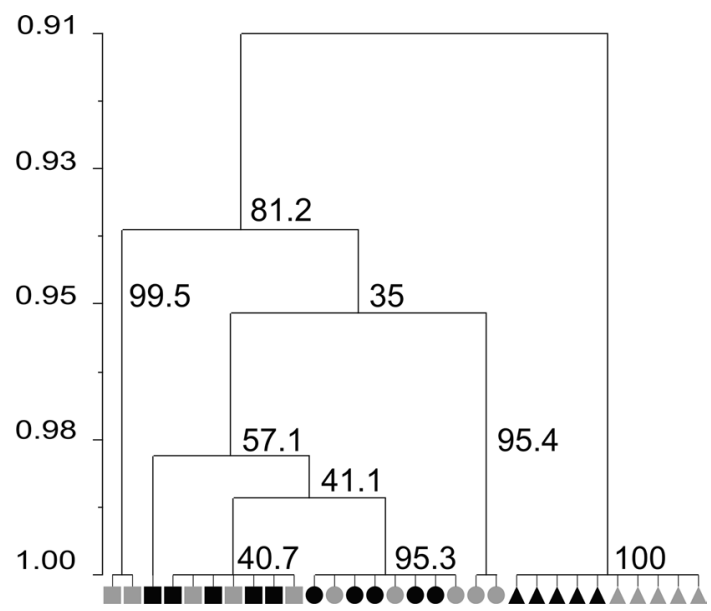

Fig. 4 Genetic diversity of three Vitis vinifera cv. Malbec clones cultivated in two contrasting vineyards. Dendrogram of genetic DICE similarity coefficient generated with UPGMA. Value of 1.00 represents complete similarity; 0.00 represents complete dissimilarity. Clones MB01 (filled circle), MB04 (filled square), and MB10 (filled triangle); vineyards Agrelo (gray) and Gualtallary (black)
Table 2 Distribution of analyzed methylation-sensitive amplified polymorphism (MSAP) epiloci observed in three Vitis vinifera cv. Malbec clones

\begin{tabular}{llll}
\hline Clone & Epiloci & & \\
\cline { 2 - 4 } & Monomorphic & Polymorphic & Total \\
\hline MB01 & $109(24 \%)$ & $309(68 \%)$ & 455 \\
MB04 & $24(8 \%)$ & $202(71 \%)$ & 283 \\
MB10 & $62(21 \%)$ & $184(62 \%)$ & 296 \\
\hline
\end{tabular}

For each clone, number and percentages of monomorphic and polymorphic epiloci are shown

to the vineyard (Supplementary Fig. S3). PCoA analysis showed that each clone was grouped apart from the others (Fig. 5a) and MB04 was the clone in which more dispersion was observed among biological replicates. Also, Gualtallary plants of MB10 showed more dispersion than Agrelo plants. Moreover, the PERMANOVA analysis of DICE dissimilarity matrices resulted in highly significant $(P \leq 0.001)$ epigenetic variance among clones, accounting for $35.8 \%$ of total variance while the contribution of vineyard to the total observed variability was of $4 \%$ (Table 3 ). Then, the effects of site on epigenetic variability were evaluated for each clone independently, observing a significant effect for MB01 and MB10, accounting for $15 \%$ and $21.8 \%$ of the total variance, respectively (Table 3 ). Similar results were visualized in the PCoA analysis, where MB01 and MB10 presented different methylation patterns associated with the vineyard, being more notorious in MB10, while plants of MB04 clone showed no differences between vineyards (Fig. 5b-d).

\section{Clones presented different methylation levels regardless of the vineyards}

On average, $49 \%$ of all MSAP fragments were non-methylated, while $30 \%$ were methylated. MLGL analysis of DNA methylation level showed significant differences among clones in the proportion of non-methylated, hemimethylated and methylated loci, while no differences were observed among vineyards (Supplementary Fig. S4). MB01 presented most hemimethylated loci; moreover, a significant lower proportion of methylated loci was observed in Gualtallary vineyard plants in comparison with the other two clones. An interaction between clone and the vineyard $(P=0.0785)$ was observed between MB01 and MB04 in the non-methylated loci (Supplementary Fig. S4).

\section{Correlation between MSAP epigenetic and phenotypic variability was detected}

Table 4 shows a high correlation between the MSAP genetic and epigenetic variability, without association between 
Fig. 5 Epigenetic variability estimated with MSAP markers in three Vitis vinifera cv. Malbec clones cultivated in two contrasting vineyards. Biplot visualization and 0.95 confidence ellipses of the principal coordinates analysis considering all evaluated samples (a) and per clone (b-d). Clones MB01 (filled circle), MB04 (filled square), and MB10 (filled triangle); vineyards Agrelo (gray) and Gualtallary (black)
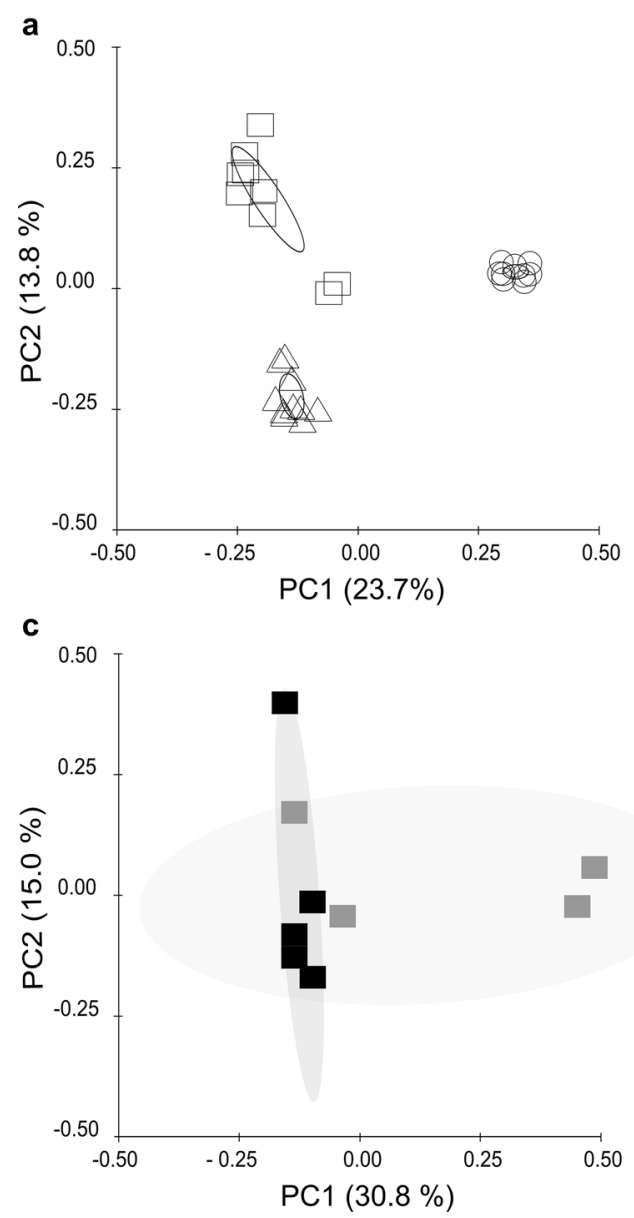

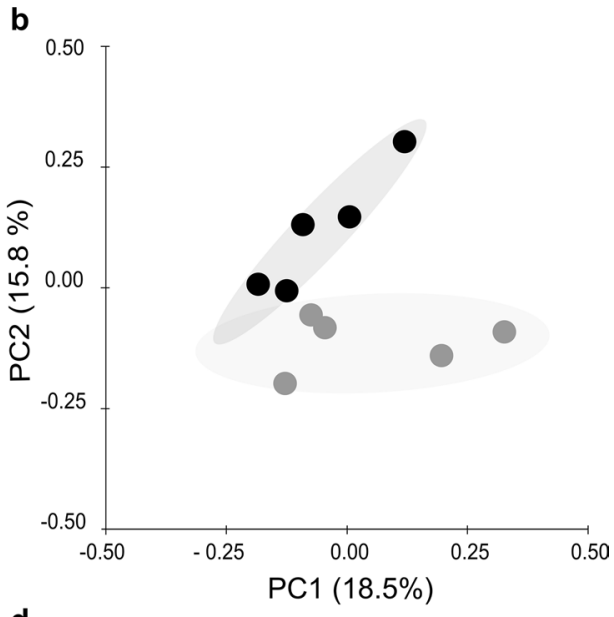

d

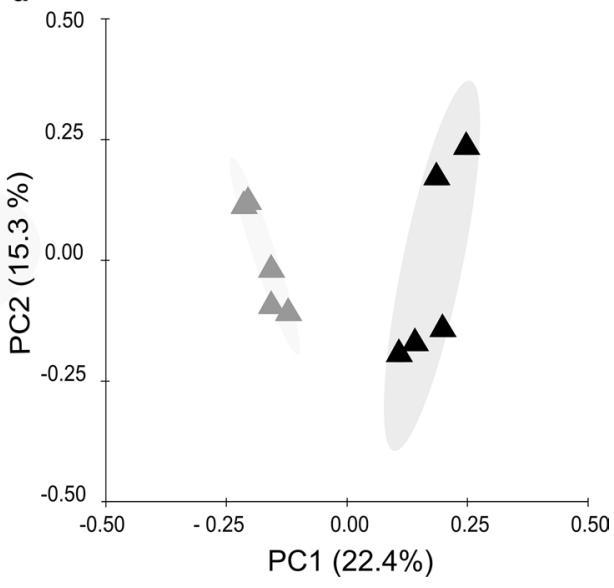

Table 3 Permutational analysis of molecular variance (PERMANOVA) for the epigenetic DICE dissimilarity matrices from methylation-sensitive amplified polymorphism (MSAP) markers in three Vitis vinifera cv. Malbec clones

\begin{tabular}{llllll}
\hline Clones & Source of variation & $d f$ & Sums of squares & $\begin{array}{l}\text { Percentage of } \\
\text { variation }\end{array}$ & $P$ value \\
\hline MB01, MB04 & Clone & 2 & 2.5288 & 35.8 & 0.000999 \\
and MB10 & Site & 1 & 0.2816 & 4 & 0.039960 \\
& Clone*site & 2 & 0.5064 & 7.2 & 0.027972 \\
& Residuals & 24 & 3.7469 & 53 & \\
MB01 & Site & 1 & 0.19633 & 15 & 0.02398 \\
\multirow{2}{*}{ MB04 } & Residuals & 8 & 1.11350 & 85 & 0.08492 \\
& Site & 1 & 0.28309 & 15.7 & \\
MB10 & Residuals & 8 & 1.52515 & 84.3 & 0.008991 \\
& Site & 1 & 0.30865 & 21.8 & \\
\hline
\end{tabular}

Permutation test with 1000 repetitions

genetic and phenotypic variability. On the other hand, epigenetic and phenotypic variability showed a small but significant linear correlation when the entire sets of data for the three clones were considered (Table 4). When clones were analyzed separately, only MB10 showed a linear correlation between epigenetic and phenotypic variability. When vineyards were analyzed separately, only Agrelo plants showed 
Table 4 Correlation Mantel test between methylation-sensitive amplified polymorphism (MSAP) genetic and epigenetic distances with their phenotypic distances

\begin{tabular}{lcc}
\hline Correlations & $R$ & $P$ value \\
\hline Genetic-epigenetic & 0.63 & $<0.0001$ \\
Genetic-phenotypic & 0.02 & 0.425 \\
Epigenetic-phenotypic & & \\
All plants & 0.15 & 0.002 \\
MB01 & -0.08 & 0.693 \\
MB04 & -0.34 & 0.97 \\
MB10 & 0.28 & 0.043 \\
Agrelo & 0.32 & $<0.0001$ \\
Gualtallary & 0.12 & 0.154 \\
\hline
\end{tabular}

Epigenetic and phenotypic correlation was performed for the entire set of data and also separately for each Vitis vinifera $\mathrm{cv}$. Malbec clone and vineyard

a linear correlation between epigenetic and phenotypic distances (Table 4).

\section{RRBS analysis reveals epigenetic differences between vineyards in MB10 plants and correlations with phenotypic traits}

Three virus-free plants of Agrelo and Gualtallary were used for RRBS analysis (Supplementary Table S1). The six samples provided methylation data for an average of 6 million, 4.5 million and 19 million of cytosines in the $\mathrm{CpG}$, $\mathrm{CpHpG}$ and $\mathrm{CpHpH}$ contexts, respectively. Of those, $7.4 \%$ of cytosines were methylated in the $\mathrm{CpG}$ context, while $3.2 \%$ and $0.5 \%$ were methylated in the $\mathrm{CpHpG}$ and $\mathrm{CpHpH}$ contexts, respectively. The samples were clustered based on the similarity of their methylation profiles. The resulting dendrogram clustered the plants by vineyard when $\mathrm{CpG}$ and $\mathrm{CpHpG}$ contexts were analyzed, but not in $\mathrm{CpHpH}$ context (Fig. 6a-c). As seen in MSAP results, MB10 Gualtallary plants also showed more dispersion than Agrelo plants.

No significant correlation was detected between the RRBS methylome dataset and the whole phenotypic dataset in either of the tree contexts. Then, sub-groups of traits with significant clone and vineyard interactions were chosen for further correlation analyses (Fig. 2). As seen in Table 5, eight phenotypic sub-groups corresponding to TSS content, quality and yield parameters were formed to establish correlations with the epigenetic variability in $\mathrm{CpG}$ and $\mathrm{CpHpG}$ contexts. Statistical significant correlations were observed for Skin DW/TSS abs and Skin DW/TSS abs/TSS conc subgroups (Table 5).

\section{RRBS analysis detected DMRs between vineyards}

RRBS analysis comparing Gualtallary and Agrelo methylomes identified 45 DMRs. Twenty-nine of those DMRs were selected by having either genes or promoter regions (Supplementary Data $\mathrm{S} 4)$. Gene ontology (GO) assignments were performed, and the main molecular functions represented by the associated DMRs were catalytic and binding (Fig. 7a), while the main biological process associated was related to metabolic process (Fig. 7b).

Associated DMRs were ranked based on the degree of the methylation difference between vineyards (Supplementary Data S4). As expected, the biggest absolute methylation difference was found in the CpG context (Bartels et al. 2018), but DMRs were also found in the $\mathrm{CpHpG}$ and $\mathrm{CpHpH}$ contexts in similar proportion. The three top differentially

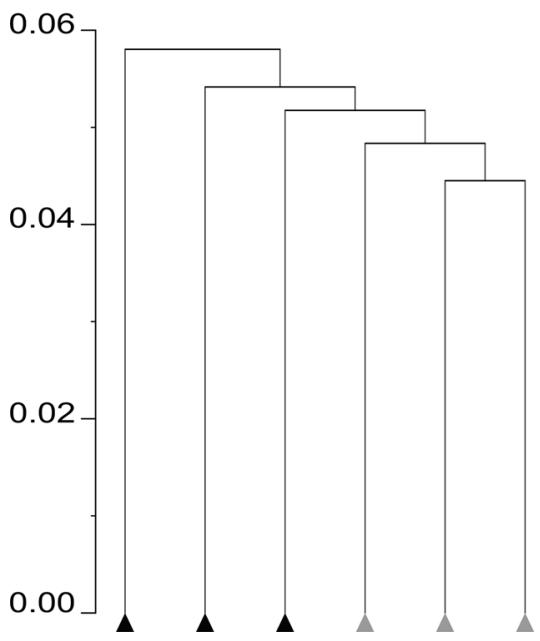

b

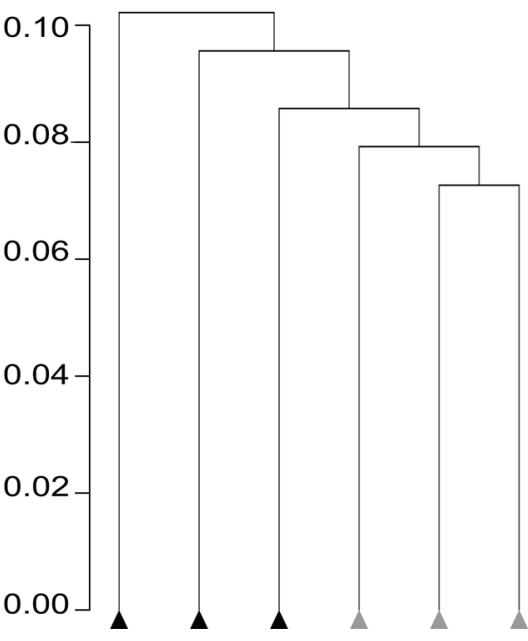

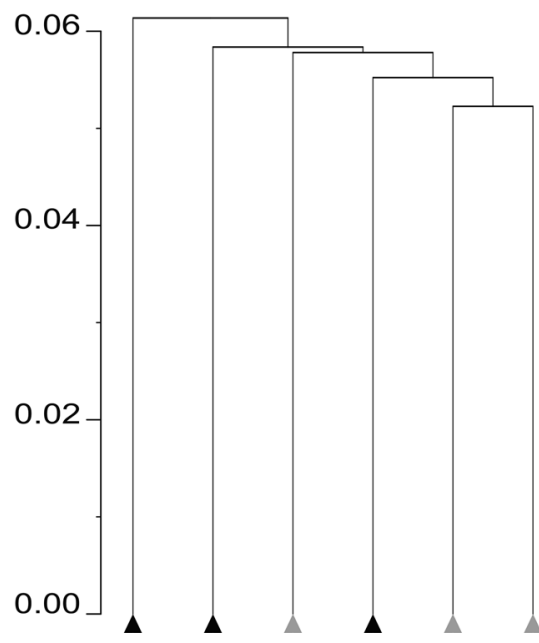

Fig. 6 RRBS epigenetic diversity of Vitis vinifera cv. Malbec MB10 clone cultivated in two contrasting vineyards. Dendrogram of correlation distance clustered with Ward's method in $\mathrm{CpG}(\mathbf{a}), \mathrm{CpHpG}(\mathbf{b})$ and $\mathrm{CpHpH}$ (c) contexts. Vineyards Agrelo (gray) and Gualtallary (black) 
Table 5 Correlation Mantel test for RRBS epigenetic distances of Vitis vinifera cv. Malbec MB10 clone

\begin{tabular}{llcc}
\hline Phenotypic variables & & CpG & CpHpG \\
\hline TSS abs/TSS conc & $R$ & 0.12 & 0.22 \\
& $P$ value & 0.31 & 0.12 \\
TP conc/TA conc & $R$ & -0.03 & 0.03 \\
TP abs/TA abs & $P$ value & 0.55 & 0.47 \\
Bunch FW/\#Berries & $R$ & -0.17 & -0.13 \\
& $P$ value & 0.71 & 0.69 \\
Skin DW/TP conc/TA conc & $R$ & -0.02 & -0.06 \\
Skin DW/TSS abs & $P$ value & 0.56 & 0.69 \\
& $P$ value & 0.29 & 0.35 \\
Skin DW/TSS conc & $R$ & 0.21 & 0.16 \\
Skin DW/TSS abs/TSS conc & $R$ & 0.54 & 0.66 \\
& $P$ value & 0.50 & 0.018 \\
& $R$ & 0.11 & 0.068 \\
& $P$ value & 0.47 & 0.56 \\
& $R$ & 0.04 & 0.016 \\
\hline
\end{tabular}

Epigenetic and phenotypic correlation was performed for $\mathrm{CpG}$ and $\mathrm{CpHpG}$ contexts and sub-groups of phenotypic traits that presented significant differences among vineyards

methylated genes were: STAS (Sulfate Transporter and Anti-Sigma factor antagonist) domain-containing protein (VIT_11s0016g04160), a putative membrane protein still uncharacterized (VIT_02s0025g03910) and $O$-acyltransferase (WSD1-LIKE; VIT_16s0098g00380); for the whole list, see Supplementary Data S4.

Some DMRs associated with genes related to hormones homeostasis and sensing could provide a hint of the epigenetic role in the determination of the different phenotypes observed between vineyards. Functional groups of genes bearing this characteristics were: i) a Oxygenase (VIT_15s0048g01960) involved brassinosteroid homeostasis and sterol metabolic process; ii) a Oxysterol-binding protein-related protein 4B-like (VIT_11s0103g00530), involved in Sterol transporter activity; iii) a transcription termination factor mTERF5 (VIT_14s0171g00230) involved in response to ABA, and salt stress regulation of transcription; and iv) an AP2/ERF (APETALA2/ethylene-responsive factor) domaincontaining protein (VIT_09s0002g08830), a transcription factor associated to ethylene response.

\section{Discussion}

Two approaches, MSAP and RRBS, were used to study the role of DNA methylation on phenotypic plasticity of three Malbec clones cultivated in two contrasting vineyards of Mendoza (Argentina). Agrelo and Gualtallary vineyards showed differences in anti-hail nets protection, soil types, daily mean air temperature, and monthly rainfall.

The phenotypic characterization of TP abs, anthocyanins (TA conc, TA abs), total soluble accumulation (TSS conc, TSS abs) and \# berries showed significant clone and vineyard interactions, where the genotype $(\mathrm{G})$ and environment (E) interacted to produce the observed phenotypes (P). Cosseau et al. (2017), proposed that G should be replaced by 'inheritance system', including both genome and epigenome (I) components that collectively interact with the environment to shape the phenotype [conceptualized as $(\mathrm{G} \times \mathrm{I}) \times$ $\mathrm{E}=\mathrm{P}]$. MB01 and MB10 clones exhibited clear phenotypic differences between vineyards, while MB04 showed stochastic distribution of biological replicates. The possibility of MB01 and MB10 to give rise to different phenotypes between vineyards is an example of developmental plasticity (Jablonka 2012), which depends on the regulatory modulation of genes. TP and TA concentrations were one of most environmentally dependent phenotypic variables. Grape germplasm shows extensive phenotypic diversity, especially for berry traits (Magris et al. 2019). The plasticity of Corvina transcriptome revealed that the phenylpropanoid pathway was one of the most environmentally dependent metabolic components (Dal Santo et al. 2013). Likewise, the

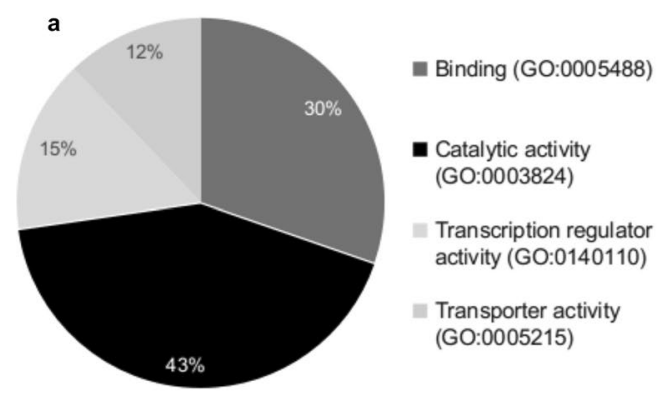

Fig. 7 Reduced representation bisulfite sequencing analysis in plants of Vitis vinifera cv. Malbec. Gene Onthology (GO) analysis for the differentially methylated regions (DMRs) found on plants of clone
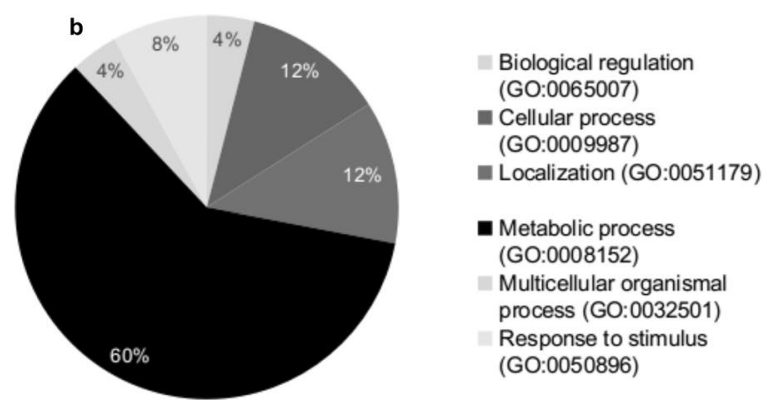

MB10 from Agrelo and Gualtallary vineyards. The percentage of GO category-related genes is shown insight the pie chart. a GO molecular function. b GO biological process 
accumulation of hydroxycinnamic, hydroxybenzoic acids, and flavonols was found to be highly responsive to the environment (Dal Santo et al. 2016).

For the analysis of environmentally induced changes in DNA methylation, it was relevant to confirm the clonal homogeneity among plants of Agrelo and Gualtallary. Clonal homogeneity removes the influence of the genetic background, thus allowing within and among genotypes comparisons (Ahn et al. 2017). MSAP markers have been used in $V$. vinifera for clone identification (Imazio et al. 2002; Ocaña et al. 2013), extensively validated and considered highly reliable (Xie et al. 2017). Using MSAP markers, we confirmed the genetic homogeneity among samples of different vineyards. The low genetic variation found within clones and the phenotypic plasticity displayed supports $V$. vinifera as a suitable model in epigenetics.

In Malbec, methylation-based epigenetic diversity exceeds the genetic diversity among clones, suggesting an epigenetic sensitivity to environmental conditions. Similar results have been reported in other perennial (Marfil et al. 2009; Herrera and Bazaga 2010; Cara et al. 2013; Ahn et al. 2017) and annual species (Salmon et al. 2008). We observed no correlation between genetic and phenotypic variability and we can affirm that the environment had a different effect in the phenotype of the clones despite their low genetic interclone variability.

When the methylation patterns were analyzed, differences were observed among clones and sites suggesting that both genotype and environment influence the DNA methylation patterns. The Malbec clones had the greatest influence on the DNA methylation variability. The genotype influence on methylation patterns can be observed in the PCoA, while MB04 clone showed a stochastic trend in the epigenetic variability among biological replicates (similar to the observed in phenotypic analyses), MB10 presented a greater degree of epigenetic plasticity that differentiated plants according to vineyards. In line with this result, Busconi et al. (2018) studied the epigenetic stability in Crocus sativus L. and found that different accessions respond to the environment in a different way despite having a similar genetic constitution. Li et al. (2008) stated that DNA methylation pattern variations may be inter-related to DNA sequence variation. A similar conclusion was proposed by Keyte et al. (2006) with Gossypium hirsutum L. Our results are congruent with these findings, since a strong correlation between the MSAP epigenetic and genetic variability was found. A study done in three natural oak populations (Quercus lobata Née) located in contrasting environments also observed significant correlation among $\mathrm{CpG}$ methylation differences and their genetic differences analyzed as single-nucleotide differences (Platt et al. 2015). Environmentally induced methylation patterns were observed in the PCoA results for MB01 and MB10. A study of the effect of environmental and management conditions on DNA methylation variation made in Shiraz across six wine sub-regions of the Barossa wine zone (Australia), showed that MSAP methylation patterns were regiondependent despite the low genetic differentiation between sub-regions (Xie et al. 2017).

The correlation analysis between MSAP epigenetic and phenotypic variability was low, but similar to what was observed in other studies (Johannes et al. 2009; Reinders et al. 2009). This low correlation could probably be due to many small epigenetic changes across the genome rather than few changes with a radical impact. Interestingly, when the correlations were measured using MB10 separately, it shows an increased correlation compared to when all clones were used together. In summary, our MSAP results suggest that the environment may affect the phenotype through a change in the epigenome, what is known as a facultative epigenetic control of development (Bräutigam and Cronk 2018).

Clone MB10 was selected for further RRBS analysis since it presented the highest epigenetic differences among vineyards while having a low genetic variation among the replicates. RRBS analysis allows further deepening from genomic scale to specific genomics regions and also to discriminate by methylation context. The methylation profiles in $\mathrm{CpG}$ and $\mathrm{CpHpG}$ clustered the plants by vineyard, reinforcing the idea that the environmental context shapes the epigenome somehow. Furthermore, the correlation between RRBS epigenetic changes and sub-groups of selected phenotypic traits showed an increased $R$ statistically significant of ca. 0.6, indicating that the role of DNA methylation is probably not associated with the phenotypic plasticity in general, but rather with a subset of traits.

Differentially methylated regions (DMRs) among vineyards were found mainly at $\mathrm{CpG}$ context, similar to the observed in natural oak populations (Platt et al. 2015). DMRs corresponding to transcription factors and proteins with regulatory roles were identified. Some DMRs related to DNA methylation include E3 ubiquitin protein ligase (Marfil et al. 2019; Tan et al. 2019) and pentatricopeptide repeat proteins and F-box proteins (Ding et al. 2014).

Even though single gene analysis is of interest, a more robust study arises when a group of related functional genes respond to the same phenotype. Groups of genes associated with DMR with similar functionality were found, result that allows to hypothesize about the mechanistic bases and role of epigenetics in the origin of the phenotypic differences observed between vineyards. One example is the group of genes related to hormone homeostasis and signaling. Two genes related to the brassinosteroids pathway and two others related to $\mathrm{ABA}$ and ethylene may indicate a way to understand the complex hormone cross-talk in response to environmental differences between the two vineyards. Furthermore, the observed correlation between Skin DW/TSS 
abs and TSS conc with the epigenome could let us hypothesize that the increased amount of TSS (including sugars) observed in Agrelo is related to the genes associated with the DMRs. These genes are Oxygenase (VIT_15s0048g01960) involved in brassinosteroids homeostasis and sterol metabolic process, and Oxysterol-binding protein-related protein 4B-like (VIT_11s0103g00530), involved in sterol transporter activity that could be part of brassinosteroids activity control level (Ohnishi 2018). It is known that brassinosteroids possess a role in controlling the sugar partitioning in grapes (Xu et al. 2015; Babalık et al. 2020). On the other hand, the increase Skin DW found in Gualtallary could be related to two DMR: one associated with the $O$-acyltransferase (WSD1-LIKE) protein and the other with the AP2/ ERF (APETALA2/ethylene-responsive factor) transcription factor superfamily. Both DMRs were more methylated in the Gualtallary vineyard. In a previous work, we demonstrated that high UV-B levels induced hypermethylation in the Malbec genome (Marfil et al. 2019) and one hypothesis that emerges from this work is that the higher proportion of 5-methylcytosine observed in Gualtallary on these two genes is related to the high levels of UV-B radiation present in this vineyard in relation with Agrelo (Berli et al. 2010). Further studies are required to understand the effects of these differential methylation levels on gene expression. The $O$-acyltransferase (WSD1-LIKE) gene expression has been related to Arabidopsis cuticular wax biosynthesis and might be important in plant response to environmental stress (Lee and Suh 2015. Regarding the AP2/ERF (APETALA2/ ethylene-responsive factor) transcription factor superfamily, many ERF genes are ethylene-responsive, hormone that plays a role during grapevine ripening, by controlling anthocyanin accumulation (Licausi et al. 2010).

It is important to mention at this point that our RRBS analysis only screened a small percentage of the Vitis genome; therefore, it is not expected to detect the whole set of genes related to a phenotype but instead just few that may indicate possible involved mechanisms. Out of the 29 DMR that corresponded with functional regions of the genome, transcriptomic analysis through qRT-PCR will be done on the related functional gene groups mentioned above and on genes with transcription regulator activity. We pretend to know if the methylation state causes an increase or decrease on the expression of genes with functional categories. Previous research has associated DNA methylation at promoters and transcriptional start sites with transcriptional repression but the effect of gene body methylation is still unknown (Bräutigam and Cronk 2018).

Nowadays, clonal selection in grapes is the main solution to obtain diversity without modifying the identity of cultivars with worldwide reputation. Since epigenetic characterization could be considered as an additional layer of information to explain the source of natural variation among clones
(Niederhuth et al. 2016; Balao et al. 2018), in the future, we may be able to also select plants based on their epigenetic diversity. By keeping the genotype invariant, epiloci responsible for desired phenotypic traits could be mapped using epi Quantitative Trait Locus (Cosseau et al. 2017; Richards et al. 2017). Breeders could use this knowledge for creating new grapevine epiclones.

Empirical studies in productive contexts and over long time periods are needed for understanding the dynamics and adaptive importance of epigenetic variation and its effect on phenotype. Some epigenetic studies have been made on in situ plants and fewer on in situ clonal plants, but none of these studies have been conducted over long time periods (Ahn et al. 2017). In a recent study performed with clonally propagated potatoes growing during 3 years at contrasting altitudes and reciprocally transplanted, it was demonstrated that the methylation patterns are re-written every year (Ibañez et al. 2020).

Since Dal Santo et al. (2013) and Anesi et al. (2015) observed that the vintage effect masked environmentaldependent berry transcriptome and metabolome changes, grapevine epigenome long-term observations are mandatory. To this end, cuttings of the evaluated plants were extracted in 2015 from Agrelo and Gualtallary for asexual propagation in a common vineyard in Mendoza, Argentina. Our aim is to analyze with MSAP markers if the environmental-dependent epigenetic differences observed in MB10 are stable (epigenetic memory) or, on the contrary, if they reconfigure and lose their differences in a 3-year study. We believe that such study will allow us to better understand the involvement of epigenetics in the definition of the terroir, searching for specific epigenetic signatures linked to each vineyard.

Acknowledgements We are grateful to Ricardo Masuelli and Rubén Bottini (IBAM, CONICET-UNCuyo) for their valuable contribution in the study design. We thank Andrea Puebla and Pablo Alfredo Vera (IABIMO, INTA-CONICET) for the RRBS library construction and Fernando Buscema and Catena Institute of Wine (Bodegas Catena Zapata) for their contribution with the plant material and for sharing meteorological data.

Author contribution statement AV: data curation, methodology, formal analysis, writing, review and editing. VNI: data curation, methodology, formal analysis. RA: Sample collection, methodology, climate analysis. DZ: RRBS data curation, methodology, formal analysis. SA: Funding acquisition, RRBS analysis design, result analysis. SGT: RRBS analysis design, virus analysis. CFM: project conception and administration, funding acquisition, methodology, result analysis, supervision and writing. FJB: project conception and administration, funding acquisition, methodology, result analysis, supervision and writing.

Funding AV and VNI are fellows of the Consejo Nacional de Investigaciones Científicas y Técnicas (CONICET). This work was supported by Universidad Nacional de Cuyo (SECTyP-A043 and SIIP 06/A706), Agencia Nacional de Promoción Científica y Tecnológica (PICT-201-110 and PICT-2015-1532) and CONICET (PUE-2016 CONICET-IBAM) 


\section{Compliance with ethical standards}

Conflicts of interest The authors declare that they have no conflicts of interest.

Availability of data and material The datasets generated and/or analyzed during the current study are available from the corresponding author on reasonable request.

Code availability Not applicable.

\section{References}

Ahn J, Franklin SB, Douhovnikoff V (2017) Epigenetic variation in clonal stands of aspen. Folia Geobot. https://doi.org/10.1007/ s12224-017-9308-x

Akalin A, Kormaksson M, Li S, Garrett-Bakelman FE, Figueroa ME, Melnick A, Mason CE (2012) MethylKit: a comprehensive R package for the analysis of genome-wide DNA methylation profiles. Genome Biol. https://doi.org/10.1186/gb-2012-13-10-r87

Anesi A, Stocchero M, Dal Santo S, Commisso M, Zenoni S, Ceoldo S et al (2015) Towards a scientific interpretation of the terroir concept: plasticity of the grape berry metabolome. BMC Plant Biol. https://doi.org/10.1186/s12870-015-0584-4

Babalık Z, Demirci T, Aşcı ÖA, Baydar NG (2020) Brassinosteroids modify yield, quality, and antioxidant components in grapes (Vitis vinifera cv. Alphonse Lavallée). J Plant Growth Regul. https://doi. org/10.1007/s00344-019-09970-5

Balao F, Paun O, Alonso C (2018) Uncovering the contribution of epigenetics to plant phenotypic variation in Mediterranean ecosystems. Plant Biol. https://doi.org/10.1111/plb.12594

Baránek M, Čechová J, Raddová J, Holleinová V, Ondrušíková E, Pidra M (2015) Dynamics and reversibility of the DNA methylation landscape of grapevine plants (Vitis vinifera) stressed by in vitro cultivation and thermotherapy. PLoS One. https://doi.org/10.1371/ journal.pone.0126638

Bartels A, Han Q, Nair P, Stacey L, Gaynier H, Mosley M et al (2018) Dynamic DNA methylation in plant growth and development. Int J Mol Sci. https://doi.org/10.3390/ijms19072144

Berli FJ, Moreno D, Piccoli P, Hespanhol-Viana L, Silva MF, BressanSmith $\mathrm{R}$ et al (2010) Abscisic acid is involved in the response of grape (Vitis vinifera L.) cv. Malbec leaf tissues to ultraviolet-B radiation by enhancing ultraviolet-absorbing compounds, antioxidant enzymes and membrane sterols. Plant Cell Environ. https:// doi.org/10.1111/j.1365-3040.2009.02044.x

Berli FJ, Fanzone M, Piccoli P, Bottini R (2011) Solar UV-B and ABA are involved in phenol metabolism of Vitis vinifera L. Increasing biosynthesis of berry skin polyphenols. J Agric Food Chem. https ://doi.org/10.1021/jf200040z

Bernardo S, Dinis LT, Luzio A, Pinto G, Meijón M, Valledor L et al (2017) Kaolin particle film application lowers oxidative damage and DNA methylation on grapevine (Vitis vinifera L.). Environ Exp Bot. https://doi.org/10.1016/j.envexpbot.2017.04.002

Bonin A, Bellemain E, Eidesen PB, Pompanon F, Brochmann C, Taberlet $\mathrm{P}$ (2004) How to track and assess genotyping errors in population genetics studies. Mol Ecol. https://doi.org/10.1111/j.1365294X.2004.02346.x

Bräutigam K, Cronk Q (2018) DNA methylation and the evolution of developmental complexity in plants. Front Plant Sci. https://doi. org/10.3389/fpls.2018.01447

Busconi M, Soffritti G, Stagnati L, Marocco A, Martínez JM, De los Mozos PM, Fernandez AJ (2018) Epigenetic stability in Saffron (Crocus sativus L.) accessions during four consecutive years of cultivation and vegetative propagation under open field conditions. Plant Sci. https://doi.org/10.1016/j.plantsci.2018.09.005

Cara N, Marfil CF, Masuelli RW (2013) Epigenetic patterns newly established after interspecific hybridization in natural populations of Solanum. Ecol Evol. https://doi.org/10.1002/ece3.758

Chinnusamy V, Zhu JK (2009) Epigenetic regulation of stress responses in plants. Curr Opin Plant Biol. https://doi.org/10.1016/j. pbi.2008.12.006

Coombe BG (1995) Adoption of a system for identifying grapevine growth stages. Aust J Grape Wine R. https://doi. org/10.1111/j.1755-0238.1995.tb00086.x

Cosseau C, Wolkenhauer O, Padalino G, Geyer KK, Hoffmann KF, Grunau C (2017) (Epi)genetic inheritance in Schistosoma mansoni: a systems approach. Trends Parasitol. https://doi. org/10.1016/j.pt.2016.12.002

Dal Santo S, Tornielli GB, Zenoni S, Fasoli M, Farina L, Anesi A et al (2013) The plasticity of the grapevine berry transcriptome. Genome Biol. https://doi.org/10.1186/gb-2013-14-6-r54

Dal Santo S, Fasoli M, Negri S, D'Incà E, Vicenzi N, Guzzo F et al (2016) Plasticity of the berry ripening program in a white grape variety. Front Plant Sci. https://doi.org/10.3389/fpls.2016.00970

Ding H, Gao J, Qin C, Ma H, Huang H, Song P (2014) The dynamics of DNA methylation in maize roots under Pb stress. Int J Mol Sci. https://doi.org/10.3390/ijms151223537

Easlon HM, Bloom AJ (2014) Easy leaf area: automated digital image analysis for rapid and accurate measurement of leaf area. Appl Plant Sci. https://doi.org/10.3732/apps.1400033

Fabres PJ, Collins C, Cavagnaro TR, Rodríguez López CM (2017) A concise review on multi-omics data integration for terroir analysis in Vitis vinifera. Front Plant Sci. https://doi.org/10.3389/ fpls.2017.01065

Gambino G, Gribaudo I (2006) Simultaneous detection of nine grapevine viruses by multiplex reverse transcription-polymerase chain reaction with coamplification of a plant RNA as internal control. Phytopathology. https://doi.org/10.1094/PHYTO-96-1223

Gambino G, Perrone I, Gribaudo I (2008) A rapid and effective method for RNA extraction from different tissues of grapevine and other woody plants. Phytochem Anal. https://doi.org/10.1002/pca.1078

Henderson IR, Jacobsen SE (2007) Epigenetic inheritance in plants. Nature. https://doi.org/10.1038/nature05917

Herrera CM, Bazaga P (2010) Epigenetic differentiation and relationship to adaptive genetic divergence in discrete populations of the violet Viola cazorlensis. New Phytol. https://doi.org/10.111 1/j.1469-8137.2010.03298.x

Ibañez VN, Masuelli RW, Marfil CF (2020) Environmentally induced phenotypic plasticity and DNA methylation changes in a wild potato growing in two contrasting Andean experimental gardens. Heredity. https://doi.org/10.1038/s41437-020-00355-z

Imazio S, Labra M, Grassi F, Winfield M, Bardini M, Scienza A (2002) Molecular tools for clone identification: the case of the grapevine cultivar 'Traminer'. Plant Breed. https://doi.org/10.10 46/j.1439-0523.2002.00762.x

Jablonka E (2012) Epigenetic inheritance and plasticity: the responsive germline. Prog Biophys Mol Biol. https://doi.org/10.1016/j.pbiom olbio.2012.08.014

Jaillon O, Aury JM, Noel B, Policriti A, Clepet C, Casagrande A et al (2007) The grapevine genome sequence suggests ancestral hexaploidization in major angiosperm phyla. Nature. https://doi. org/10.1038/nature06148

Johannes F, Porcher E, Teixeira FK, Saliba-Colombani V, Simon M, Agier $\mathrm{N}$ et al (2009) Assessing the impact of transgenerational epigenetic variation on complex traits. PLoS Genet. https://doi. org/10.1371/journal.pgen.1000530

Keller M (2010) Managing grapevines to optimise fruit development in a challenging environment: a climate change primer 
for viticulturists. Aust J Grape Wine R. https://doi.org/10.111 1/j.1755-0238.2009.00077.x

Keyte AL, Percifield R, Liu B, Wendel JF (2006) Infraspecific DNA methylation polymorphism in cotton (Gossypium hirsutum L.). J Hered. https://doi.org/10.1093/jhered/es1023

Lee SB, Suh MC (2015) Cuticular wax biosynthesis is up-regulated by the MYB94 transcription factor in Arabidopsis. Plant Cell Physiol. https://doi.org/10.1093/pcp/pcu142

Li Y, Shan X, Liu X, Hu L, Guo W, Liu B (2008) Utility of the methylation-sensitive amplified polymorphism (MSAP) marker for detection of DNA methylation polymorphism and epigenetic population structure in a wild barley species (Hordeum brevisubulatum). Ecol Res. https://doi.org/10.1007/s11284-007-0459-8

Licausi F, Giorgi FM, Zenoni S, Osti F, Pezzotti M, Perata P (2010) Genomic and transcriptomic analysis of the AP2/ ERF superfamily in Vitis vinifera. BMC Genom. https://doi. org/10.1186/1471-2164-11-719

Lodhi M, Ye GN, Weeden N, Reisch B (1994) A simple and efficient method for DNA extraction from grapevine cultivars, Vitis species and Ampelopsis. Plant Mol Biol Rep. https://doi.org/10.1007/ BF02668658

Magris G, Di Gaspero G, Marroni F, Zenoni S, Tornielli GB, Celii $M$ et al (2019) Genetic, epigenetic and genomic effects on variation of gene expression among grape varieties. Plant J. https:// doi.org/10.1111/tpj.14370

Marfil CF, Camadro EL, Masuelli RW (2009) Phenotypic instability and epigenetic variability in a diploid potato of hybrid origin, Solanum ruiz-lealii. BMC Plant Biol. https://doi. org/10.1186/1471-2229-9-21

Marfil CF, Ibañez V, Alonso R, Varela A, Bottini R, Masuelli R, Berli $F(2019)$ Changes in grapevine DNA methylation and polyphenols content induced by solar ultraviolet-B radiation, water deficit and abscisic acid spray treatments. Plant Physiol Biochem. https://doi. org/10.1016/j.plaphy.2018.12.021

Niederhuth CE, Bewick AJ, Ji L, Alabady MS, Kim KD, Li Q et al (2016) Widespread natural variation of DNA methylation within angiosperms. Genome Biol. https://doi.org/10.1186/s1305 9-016-1059-0

Norouzitallab P, Baruah K, Vanrompay D, Bossier P (2019) Can epigenetics translate environmental cues into phenotypes? Sci Total Environ. https://doi.org/10.1016/j.scitotenv.2018.08.063

Ocaña J, Walter B, Schellenbaum P (2013) Stable MSAP markers for the distinction of Vitis vinifera cv Pinot Noir clones. Mol Biotechnol. https://doi.org/10.1007/s12033-013-9675-3

Ohnishi T (2018) Recent advances in brassinosteroid biosynthetic pathway: insight into novel brassinosteroid shortcut pathway. J Pestic Sci. https://doi.org/10.1584/jpestics.D18-040

Oksanen J, Blanchet FG, Friendly M, Kindt R, Legendre P, McGlinn D, Minchin PR, O'hara RB, Simpson GL, Solymos P, Stevens MHH, Eduard Szoecs E, Wagner H (2019) Vegan: community ecology package. R package version 2.5-6. https://CRAN.R-project.org/ package $=$ vegan. Accessed 10 Oct 2020

Pigliucci M (2005) Evolution of phenotypic plasticity: where are we going now? Trends Ecol Evol. https://doi.org/10.1016/j. tree.2005.06.001

Platt A, Gugger PF, Pellegrini M, Sork VL (2015) Genome-wide signature of local adaptation linked to variable $\mathrm{CpG}$ methylation in oak populations. Mol Ecol. https://doi.org/10.1111/mec.13230

Poojari S, Alabi OJ, Okubara PA, Naidu RA (2016) SYBR ${ }^{\circledR}$ Greenbased real-time quantitative reverse-transcription PCR for detection and discrimination of grapevine viruses. J Virol Methods. https://doi.org/10.1016/j.jviromet.2016.05.013
Reinders J, Wulff BBH, Mirouze M, Marí-Ordóñez A, Dapp M, Rozhon W et al (2009) Compromised stability of DNA methylation and transposon immobilization in mosaic Arabidopsis epigenomes. Genes Dev. https://doi.org/10.1101/gad.524609

Richards CL, Alonso C, Becker C, Bossdorf O, Bucher E, ColoméTatché M et al (2017) Ecological plant epigenetics: evidence from model and non-model species, and the way forward. Ecol Lett. https://doi.org/10.1111/ele.12858

Sáez-Laguna E, Guevara MÁ, Díaz L, Sánchez-Gómez D, Collada C, Aranda I, Cervera MT (2014) Epigenetic variability in the genetically uniform forest tree species Pinus pinea L. PLoS One. https ://doi.org/10.1371/journal.pone.0103145

Salmon A, Clotault J, Jenczewski E, Chable V, Manzanares-Dauleux MJ (2008) Brassica oleracea displays a high level of DNA methylation polymorphism. Plant Sci. https://doi.org/10.1016/j.plant sci.2007.09.012

Schellenbaum P, Mohler V, Wenzel G, Walter B (2008) Variation in DNA methylation patterns of grapevine somaclones (Vitis vinifera L.). BMC Plant Biol. https://doi.org/10.1186/1471-2229-8-78

Schulz B, Eckstein RL, Durka W (2013) Scoring and analysis of methylation-sensitive amplification polymorphisms for epigenetic population studies. Mol Ecol Resour. https://doi. org/10.1111/1755-0998.12100

Sneath PH, Sokal RR (1973) Numerical Taxonomy. The principles and practice of numerical classification. San Francisco

Tan B, Lian X, Cheng J, Zeng W, Zheng X, Wang W et al (2019) Genome-wide identification and transcriptome profiling reveal that E3 ubiquitin ligase genes relevant to ethylene, auxin and abscisic acid are differentially expressed in the fruits of melting flesh and stony hard peach varieties. BMC Genom. https://doi. org/10.1186/s12864-019-6258-0

This P, Lacombe T, Thomas MR (2006) Historical origins and genetic diversity of wine grapes. Trends Genet. https://doi.org/10.1016/j. tig.2006.07.008

Tyunin AP, Kiselev KV (2016) Alternations in VaSTS gene cytosine methylation and t-resveratrol production in response to UV-C irradiation in Vitis amurensis. Plant Cell Tissue Organ. https://doi. org/10.1007/s11240-015-0872-6

Xie H, Konate M, Sai N, Tesfamicael KG, Cavagnaro T, Gilliham M et al (2017) Global DNA methylation patterns can play a role in defining terroir in grapevine (Vitis vinifera cv. Shiraz). Front Plant Sci. https://doi.org/10.3389/fpls.2017.01860

Xu F, Xi Z, Zhang H, Zhang C, Zhang Z (2015) Brassinosteroids are involved in controlling sugar unloading in Vitis vinifera 'Cabernet Sauvignon' berries during véraison. Plant Physiol Biochem. https ://doi.org/10.1016/j.plaphy.2015.06.005

Yap IV, Nelson RJ (1996) WinBoot: a program for performing bootstrap analysis of binary data to determine the confidence limits of UPGMA-based dendrograms. International Rice Research Institute, Philippines

Zhang H, Lang Z, Zhu J (2018) Dynamics and function of DNA methylation in plants. Nat Rev Mol Cell Biol. https://doi.org/10.1038/ s41580-018-0016-Z

Publisher's Note Springer Nature remains neutral with regard to jurisdictional claims in published maps and institutional affiliations. 